\title{
Análise da influência do plástico mole na resistência ao cisalhamento de resíduos sólidos urbanos
}

\author{
The influence of soft plastic in shear strength analysis of municipal solid waste
} Christiane Correa', José Fernando Jucá2, Eduarda Motta ${ }^{3}$

口-

\section{RESUMO}

Apresenta-se uma análise da resistência ao cisalhamento de resíduos sólidos urbanos com redução de termoplásticos em aterros sanitários. Através de ensaios de laboratório, foi realizada uma análise comparativa entre os dois principais termoplásticos (polietileno de alta e baixa densidade) presentes em aterros sanitários brasileiros. Investiga-se, a partir de ensaios de resistência à tração dos plásticos e de ensaios de cisalhamento direto de amostras preparadas com diferentes percentagens de plásticos misturados a um material granular, simulando resíduos sólidos estabilizados, a variação dos parâmetros de resistência dos RSU caso as sacolas plásticas sejam retiradas dos supermercados. Os resultados confirmam a importância dos plásticos, pois são eles os responsáveis pelos valores elevados dos parâmetros de resistência, devido às forças de tração provocadas por estas fibras.

Palavras-chave: geotecnia ambiental; resistência ao cisalhamento dos RSU; parâmetros de resistência e plásticos moles.

\begin{abstract}
This thesis presents an analysis of the shear strength of municipal solid waste with reduced thermoplastic in landfills. Through laboratory testing was performed a comparative analysis between the two main thermoplastics (high and low density polyethylene) present in Brazilians landfills. It investigates the variation of the strength parameters of MSW if plastic bags are removed from supermarkets from tensile tests of plastics and direct shear tests of samples prepared with different percentages of mixed plastics to a granular material simulating solid waste stabilized,. The results confirm the importance of plastics, because they are responsible for the high values of strength parameters due to tensile forces caused by these fibers.
\end{abstract}

Keywords: environmental geotecnical; MSW shear strength; strength parameters e soft plastics.

\section{INTRODUÇÃO}

Nos últimos anos, a legislação brasileira vem se tornando mais severa; com isto, alguns assuntos vem gerando grande polêmica na sociedade. Um dos temas abordados é sobre a proibição do uso das sacolas plásticas em supermercados. Este assunto tomou força em março de 2011, quando entrou em vigor a lei no 9.529/08, que "Dispõe sobre a substituição do uso de saco plástico de lixo e de sacola plástica por saco de lixo ecológico e sacola ecológica, e dá outras providências" em Belo Horizonte (MG) (BELO HORIZONTE, 2008); e em maio do mesmo ano foi sancionada a lei no 15.374 que "Dispõe sobre a proibição da distribuição gratuita ou venda de sacolas plásticas a consumidores em todos os estabelecimentos comerciais do Município de São Paulo, e dá outras providências", que passou a valer em janeiro de 2012 (SÃO PAULO, 2011).

É possível encontrar iniciativas que coíbem o uso de sacolas plásticas há pelo menos uma década em vários lugares do mundo. Em alguns casos, para reduzir o consumo das embalagens de polietileno, os governos locais resolveram cobrar uma taxa do consumidor que quiser usar o modelo tradicional.

A decisão de retirar ou não as sacolas dos supermercados do Brasil ainda não está definida, mas, segundo Faria (2012), o movimento

Trabalho realizado na Universidade Federal de Pernambuco (UFPE) - Recife (PE), Brasil.

'Mestre em Engenharia Civil (Geotecnia) pela UFPE. Doutoranda pela UFPE - Recife (PE), Brasil.

2Pós Doutor pela Universidade de São Paulo (USP). Professor da UFPE - Recife (PE), Brasil.

${ }^{3}$ Doutora em Engenharia Civil (Geotecnia) pela UFPE. Engenheira Civil do Departamento Nacional de Infraestrutura de Transportes (DNIT) - Recife (PE), Brasil.

Endereço para correspondência: Christiane Lyra Corrêa - Rua Jornalista Guerra de Holanda, 158/2602 - Casa Forte - 52061 -010 - Recife-PE, Brasil -

E-mail: christiane.lyra@gmail.com

Recebido: 15/10/13 - Aceito: 08/12/14 - Reg. ABES: 125006 
vem ganhando corpo mundialmente e está em consonância ao Plano de Ação para Produção e Consumo Sustentáveis (PPCS) do Governo Federal, assim como, com a Política Nacional de Resíduos Sólidos, que entrará em vigor em 2014, e orientação e esforços do Ministério do Meio Ambiente e do Governo do Estado de São Paulo de reduzir as fontes poluidoras do meio ambiente.

Dentre os fatores que induziram à criação destas leis, destacam-se problemas de destinação inadequada que podem ocasionar enchentes devido ao entupimento de galerias de drenagem pelos plásticos e que podem trazer prejuízos à fauna devido à presença de sacolas nos rios e mares. Outros argumentos estão relacionados à produção do polietileno que, como subproduto do petróleo, é uma das causas do aquecimento global e, finalmente, com relação à imensa geração de resíduos sólidos urbanos. Segundo Cintra (2011), estima-se que, na cidade de São Paulo, sejam utilizadas mais de 600 milhões de sacolas descartáveis por mês.

O principal destino final destas sacolas plásticas é em aterro de Resíduos Sólidos Urbanos (RSU). De acordo com estudos experimentais, os plásticos chegam a ocupar 50\% em volume dos materiais presentes em um aterro de RSU ao longo do tempo. A disposição final e o tratamento destes resíduos em aterros sanitários são assuntos bastantes expressivos devido à grande preocupação na conservação do meio ambiente. Os danos causados pela decomposição dos elementos que compõem os resíduos, quando não tratados adequadamente, podem ser nocivos ao meio ambiente e, consequentemente, ao ser humano.

A alteração do comportamento mecânico dos aterros sanitários devido à redução da quantidade de plásticos aterrada foi uma questão que despertou interesse no tocante ao tema da proibição do uso das sacolas, uma vez que os plásticos, como elementos fibrosos constituintes dos RSU, exercem um efeito de reforço na resistência ao cisalhamento a partir da sua resistência à tração. Desta forma, para se avaliar mudanças neste comportamento, é preciso investigar o desempenho dos tipos plásticos que deixarão de ser enviados e os que continuarão a serem enviados para os aterros.

No Brasil, o comportamento mecânico de aterros de RSU vem sendo tratado segundo os métodos clássicos da mecânica dos solos. Tal fato se dá porque a literatura é escassa neste assunto, sendo necessário, muitas vezes, buscar parâmetros oriundos da literatura internacional, que na maioria dos casos refere-se aos resíduos de composição completamente diferente e condições climáticas bastante distintas.

Sabe-se que os RSU têm uma composição bastante heterogênea em tamanho, forma e tipo dos seus componentes. Assim, para analisar seu comportamento mecânico, esta composição é comumente dividida em duas matrizes: básica (componentes não fibrosos) e reforço (plástico, têxteis, entre outros). Enquanto a primeira é responsável predominantemente pela resistência à compressão, a segunda é, principalmente, responsável pela tração (JESSBERGER et al., 1995).

\section{METODOLOGIA}

\section{Programa de Investigação}

Para a análise da contribuição dos plásticos moles na resistência ao cisalhamento dos RSU foi desenvolvido um programa de investigação de laboratório. Este programa teve por objetivo avaliar as variáveis envolvidas na resistência ao cisalhamento, realizando um comparativo entre os dois principais tipos de plásticos moles encontrados em aterros sanitários da Região Metropolitana do Recife (PE) (tipo polietileno de alta densidade - PEAD e o polietileno de baixa densidade - PEBD). Os efeitos que o acréscimo desses tipos de plásticos podem beneficiar ou não no comportamento mecânico dos resíduos, caso as sacolas plásticas saiam de circulação, são analisados por meio de ensaios de cisalhamento direto e resistência à tração.

\section{Materiais}

Para avaliar a contribuição dos plásticos moles na resistência dos RSU a partir de ensaios de cisalhamento direto, foi criado um modelo que simulasse a massa de resíduo estabilizada misturada aleatoriamente com plástico mole em diferentes percentagens encontradas na literatura. As amostras foram montadas com base nos dados de composição gravimétrica dos RSU publicados por Alcântara (2007) que determinou os percentuais para os diferentes tipos de plásticos.

Os materiais utilizados neste estudo foram o polietileno de alta densidade (PEAD) e o polietileno de baixa densidade (PEBD), pois como visto anteriormente, esses dois termoplásticos fazem parte do grupo de plástico mole. O PEAD foi obtido a partir de sacolas plásticas distribuídas em supermercados da região metropolitana do Recife, enquanto o PEBD foi adquirido basicamente de embalagens de fraldas geriátrica e infantil de variadas marcas. Para esta pesquisa, não foi necessária a separação por cor.

Com a finalidade de compor a matriz básica do experimento, foi utilizada areia obtida no laboratório de estruturas do Departamento de Engenharia Civil da Universidade Federal de Pernambuco (UFPE), para simular os materiais inertes da massa de resíduos. Desta forma, ao misturar esta areia com o reforço dos plástico, estaria simulando os resíduos antigo.

\section{Métodos}

\section{Resistência à Tração}

A resistência mecânica das amostras de PEAD e PEBD foram avaliadas através do ensaio mecânico de tração.

Os ensaios são realizados através da aplicação de uma solicitação ao material sob condições controladas, geralmente deformação a velocidade constante, até a ruptura do material ou até que a tensão ou deformação alcance um valor pré-estabelecido. Durante o experimento, a carga ou tensão suportada pelo material (resposta do material) e a deformação a ele imposta são registradas (CANEVAROLO, 2007). 
O ensaio foi realizado em uma máquina Universal, marca EMIC, modelo DL-500MF, localizada no laboratório de Materiais Poliméricos e Caracterização - LMPC do Departamento de Engenharia Química (DEQ) da UFPE, conforme representado na Figura 1.

Os corpos de prova para os ensaios de resistência à tração foram preparados segundo a norma Method for Tensile Properties of Thin Plastic Sheething (ASTM D882, 2012). Os corpos de prova apresentam formato retangular, e suas dimensões são de 25x75 mm.

A velocidade do ensaio define a taxa de deformação que será aplicada no polietileno (CANEVAROLO, 2007). Assim, para estes ensaios foi utilizada uma velocidade constante de $10 \mathrm{~mm} / \mathrm{s}$.

A temperatura é um fator que influencia no comportamento dos plásticos. Desta forma, é importante mencionar que o ensaio foi realizado a uma temperatura de $25 \pm 1^{\circ} \mathrm{C}$.

Foram utilizados 8 amostras de cada (PEAD e PEBD) devido a grande chance de erro nos ensaios, pois o plástico flexível, como são conhecidos, tendem a romper na própria garra do equipamento.

\section{Ensaio de Cisalhamento Direto}

A metodologia do ensaio de cisalhamento é baseada no critério de ruptura de Coulomb. Apesar do ensaio ter sido idealizado para solos, como em muitas outras situações que não existe metodologia específica para RSU, utiliza-se o mesmo conceito para realização dos ensaios em amostras de RSU, no caso, para mistura areia/plástico.

O ensaio de resistência ao cisalhamento foi realizado com corpos de prova moldados com diferentes percentuais de plásticos. Para o termoplástico PEAD, realizaram-se ensaios com percentuais de 1 a $6 \%$ e para o PEBD, os percentuais foram de 1 a $4 \%$.

\section{Preparação das Amostras e Moldagem dos Corpos de Prova}

A metodologia adotada para a preparação das amostras e moldagem dos corpos de prova consta de quatro etapas:

1. Determinação da densidade do solo da mistura e plástico - adotou-se para este trabalho a densidade mínima da areia $14,23 \mathrm{kN} \cdot \mathrm{m}^{-3}$. Para o plástico adotou-se o mínimo para projetos de aterros de $7,0 \mathrm{kN} \cdot \mathrm{m}^{-3}$.

2. Preparação da amostra de plástico - para determinar o tamanho das amostras de plástico levou-se em consideração as dimensões da caixa cisalhante, que é de 101,6 x 101,6 x 44,5 mm com um volume de $459.350 \mathrm{~mm}^{3}$. Além disso, foi necessário um comprimento de amostra suficiente para que o material granular o segurasse com seu peso próprio, pois o plástico é extremamente volumoso, dificultando sua colocação na caixa. A princípio, a relação do comprimento do plástico com a caixa era de $1 / 10$, porém, como explicado anteriormente sobre a dificuldade de colocação do mesmo na caixa com o material granular, adotou-se para amostra de plástico um comprimento de $50 \mathrm{~mm}$ e largura de $10 \mathrm{~mm}$, com uma relação de $1 / 2$.
3. Determinação do peso de plástico e areia para as diferentes amostras através das Equações 1 e 2.

$\mathrm{PP}=$ Vol. da caixa $\mathrm{x}$ Dens. do $\mathrm{P} \mathrm{x} \%$ do $\mathrm{P}$

PA $=$ Vol. da caixa $\mathrm{x}$ Dens. da A x \% da A

onde:

P.P.: peso do plástico;

Vol. da caixa: volume da caixa cisalhante;

Dens. do P.: densidade adotada para o plástico;

$\%$ do P.: percentagem do plástico;

P.A.: peso da areia;

Dens. da A.: densidade adotada para areia;

$\%$ da A.: percentagem da areia.

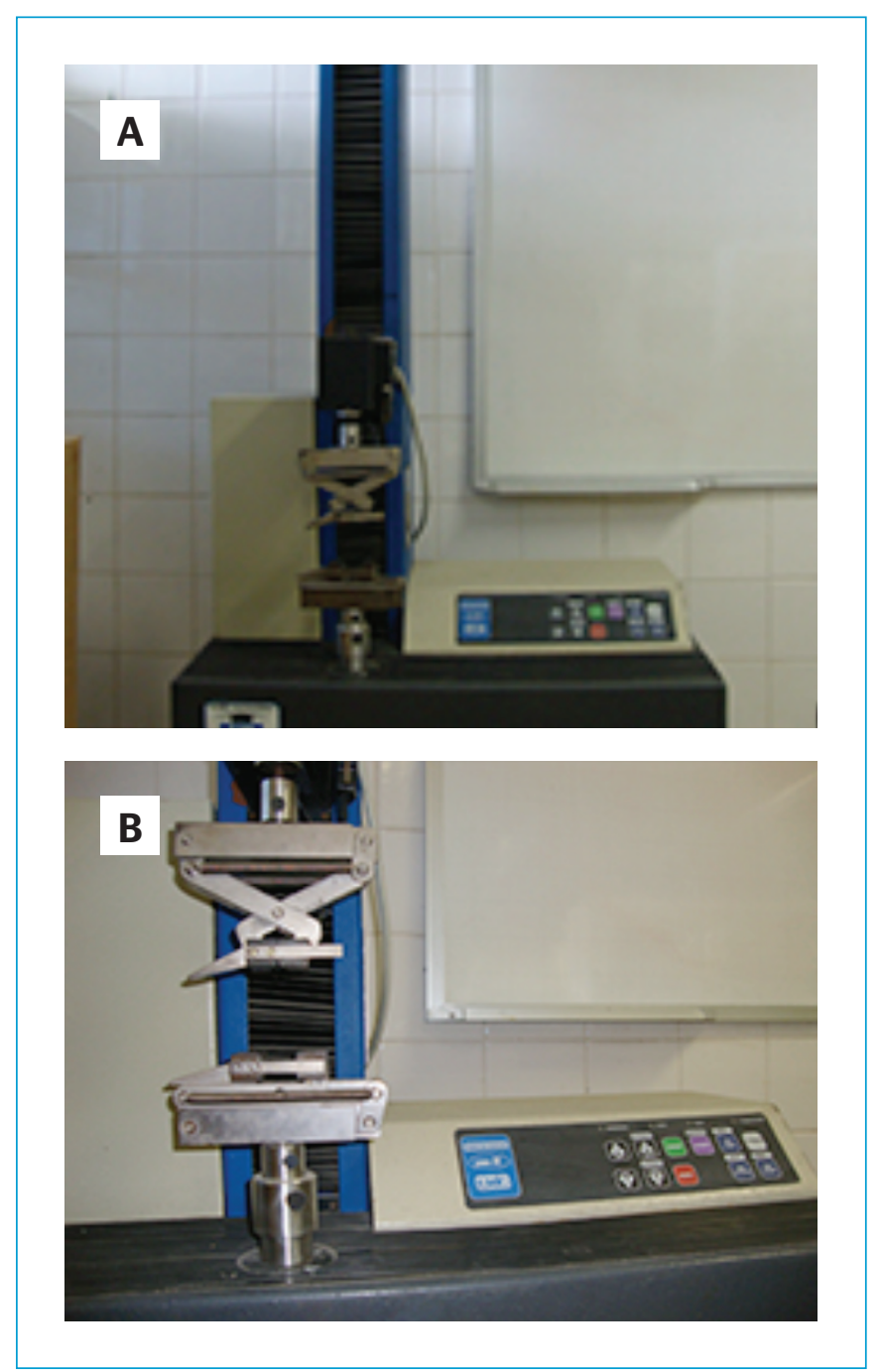

Figura 1 - Equipamento para ensaio de tração: Máquina universal, marca EMIC, modelo DL-500MF. 
4. Moldagem do corpo de prova na caixa de cisalhamento - para colocar a mistura dentro da caixa, primeiro foi feita uma mistura prévia nos dois materiais com auxilio de uma cápsula. Desta forma, o plástico ficaria disposto de forma aleatória dentro da caixa. Como em alguns casos o percentual de plástico tinha um elevado volume, foi necessária uma vibração e compactação manual para assentar a amostra de forma correta na caixa.

\section{Metodologia dos Ensaios}

O equipamento utilizado para os ensaios de cisalhamento direto foi uma prensa de cisalhamento direto produzida pelo Ronald Top S/A (Figura 2), com sistema de aplicação de tensão normal a partir de pesos em pendural.
Nas leituras dos deslocamentos verticais e horizontais foram utilizados extensômetros com sensibilidade de 0,01 mm da marca Mitutoyo. A força horizontal foi determinada a partir de um anel dinamométrico de constante de $0.16 \mathrm{kgf} \cdot \mathrm{div}^{-1}$ e capacidade de $500 \mathrm{kgf}$. As tensões normais foram aplicadas e mantidas até a estabilização dos deslocamentos. Para estes ensaios, esta estabilização se deu em torno de 45 minutos para percentuais de plástico elevados e tempo inferior para percentuais menores. Para padronizar, utilizou-se esse tempo para todos os ensaios.

O cisalhamento dos corpos de prova para cada tensão normal aplicada foi realizado com velocidade constante de $0,483 \mathrm{~mm} \cdot \mathrm{min}^{-1}$. Como critério de ruptura, adotou-se os valores de pico da tensão cisalhante ou os valores máximos, nos ensaios da areia sem plástico. Já nos
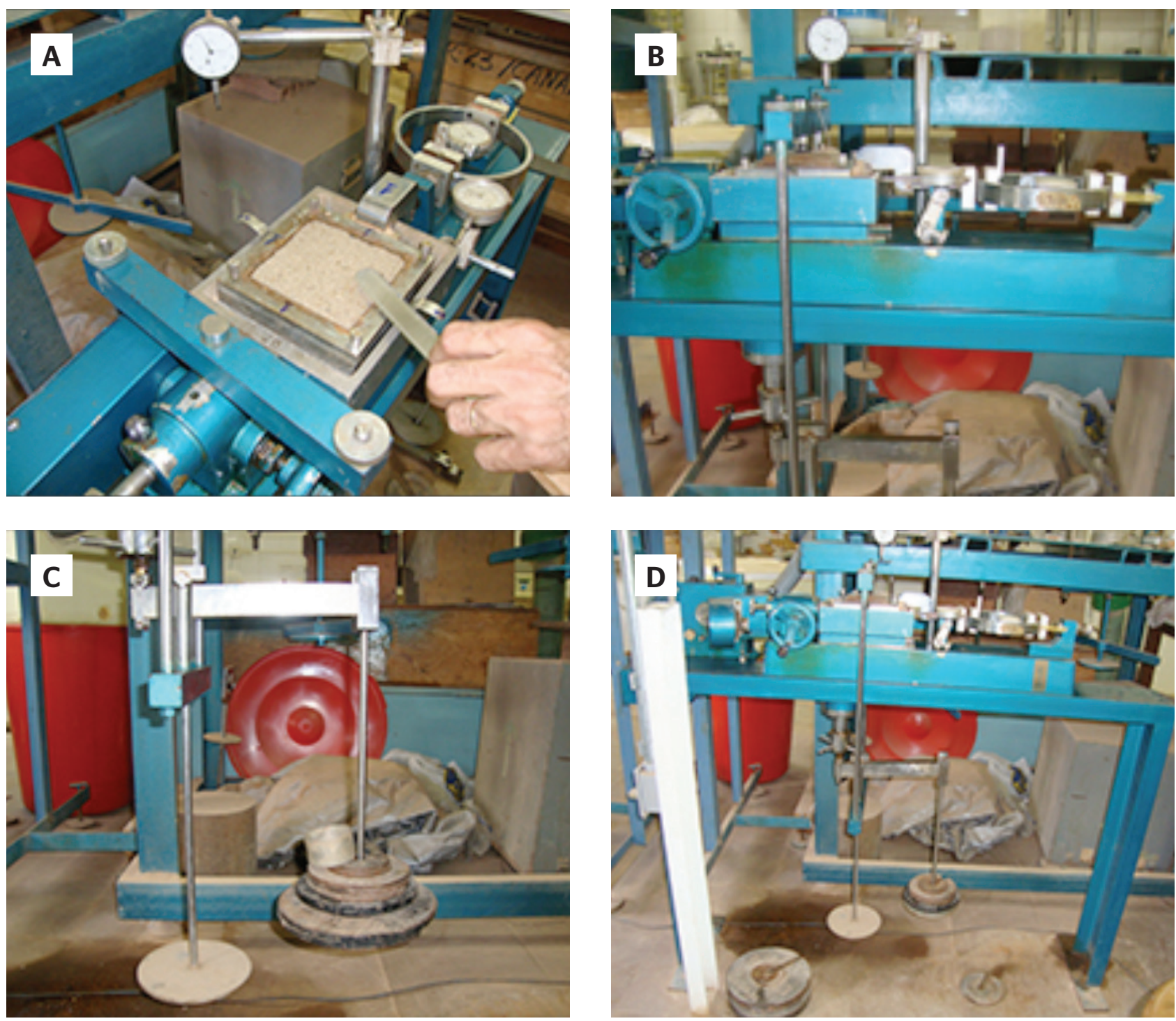

Figura 2 - Equipamento para ensaio de cisalhamento direto: Prensa de cisalhamento direto produzida por Ronald Top S/A de diferentes ângulos. 
ensaios da areia com diferentes percentuais de plástico, devido à tensão de tração do material adicionado, a curva tensão-deslocamento não indicava valores de pico bem definidos. Desta forma, os resultados foram apresentados em função do percentual de deslocamento. Os deslocamentos máximos adotados nos ensaios foram de $18 \mathrm{~mm}$.

Uma série de seis tensões normais $(25,50,75,100,150$ e $200 \mathrm{kPa})$ foi ensaiada no equipamento com corpos de prova moldados para diferentes percentuais de plástico. Normalmente, esse tipo de ensaio é realizado para uma série de quatro tensões, porém, como se buscava uma tendência à bilinearidade, adotaram-se as seis tensões citadas.

\section{RESULTADOS}

\section{Ensaio de Resistência à Tração dos Plásticos}

Os ensaios de resistência à tração foram realizados com amostras de PEAD e PEBD e os resultados são apresentados a partir dos gráficos de tensão de tração versus deslocamento relativo horizontal (Figura 3A) e força versus deslocamento relativo horizontal (Figura 3B), enquanto os correspondentes valores da tensão e força de acordo com os deslocamentos aplicados são mostrados na Tabela 1.

Nota-se que os resultados, tanto de PEAD como de PEBD, encontram-se agrupados, apresentando uma tendência, com exceção do corpo de prova número sete $(\mathrm{CP} 7)$ para $\mathrm{PEBD}$ e o corpo de prova número um (CP1) para PEAD, Tabela 1. Assim, pode-se excluir estes pontos e considerar a média dos valores que são para $\mathrm{PEAD}, \mathrm{F}=6,74 \mathrm{~N}$ e t=2,88 $\mathrm{MPa}$, enquanto que para $\mathrm{PEBD}$ são $\mathrm{F}=14,44 \mathrm{~N}$ e $\mathrm{t}=6,17 \mathrm{MPa}$.

A partir dos valores apresentados, observa-se que a resistência à tração do material de PEBD é maior do que a de PEAD. Logo, pode-se confirmar que os resultados deste trabalho estão de acordo com Silva (2005), que afirma que, quanto menor a densidade do plástico, maior a resistência à tração. Além disso, pode-se afirmar que a razão da grande diferença dos valores (praticamente o dobro) deve-se também ao fato do material de PEBD conter muitos aditivos, devido a pigmentação usada para a estampa das embalagens.

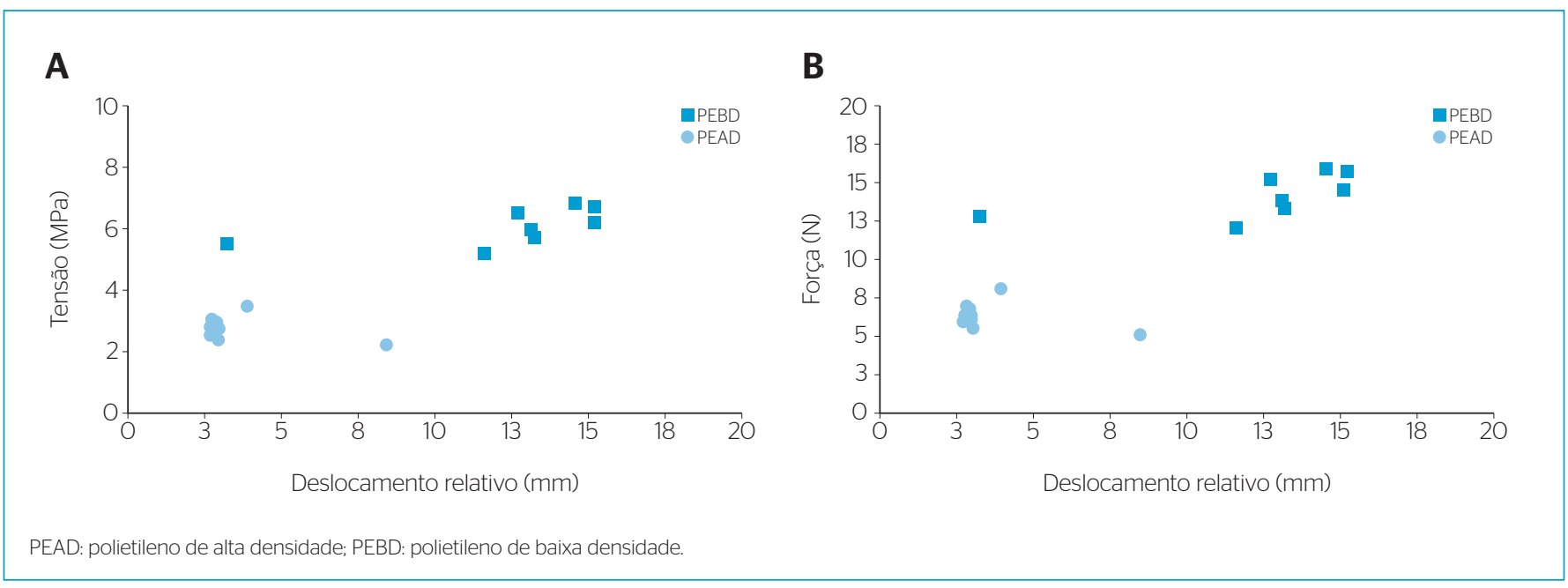

Figura 3 - (A) Tensão de tração versus deslocamento relativo; (B) Força versus deslocamento relativo.

Tabela 1 - Valores das tensões e forças para respectivos deslocamentos relativos.

\begin{tabular}{|c|c|c|c|c|c|c|c|}
\hline & \multicolumn{3}{|c|}{ PEBD } & & \multicolumn{3}{|c|}{ PEAD } \\
\hline & Força (N) & Desl. (mm) & Tensão (MPa) & & Força (N) & Desl. (mm) & Tensão (MPa) \\
\hline $\mathrm{CP} 1$ & 15,21 & 12,67 & 6,499 & $\mathrm{CP} 1$ & 5,205 & 8,472 & 2,224 \\
\hline CP2 & 12,08 & 11,64 & 5,161 & $\mathrm{CP} 2$ & 8,146 & 3,906 & 3,481 \\
\hline CP3 & 14,59 & 15,14 & 6,237 & CP3 & 7,029 & 2,824 & 3,004 \\
\hline CP4 & 13,96 & 13,16 & 5,968 & CP4 & 7,029 & 2,918 & 3,004 \\
\hline CP5 & 15,79 & 15,23 & 6,747 & CP5 & 5,677 & 2,965 & 2,426 \\
\hline CP6 & 13,48 & 13,18 & 5,759 & CP6 & 6,479 & 2,965 & 2,769 \\
\hline CP7 & 12,91 & 3,233 & 5,517 & CP7 & 6,133 & 2,73 & 2,621 \\
\hline CP8 & 15,95 & 14,53 & 6,815 & CP8 & 6,668 & 2,73 & 2,849 \\
\hline
\end{tabular}

PEAD: polietileno de alta densidade; PEBD: polietileno de baixa densidade. 


\section{Comparação dos ensaios com polietileno de alta densidade e polietileno de baixa densidade}

Para realizar um comparativo entre os resultados dos ensaios das amostras de areia com PEAD e PEBD foram elaborados gráficos com as envoltórias de resistência para diferentes percentuais de polietileno com diferentes deslocamentos relativos horizontais e tensão cisalhante versus deslocamentos relativos horizontais para as amostras de $100 \%$ de areia e diferentes percentuais de polietilenos para tensões normais de $25 \mathrm{kPa}$ e $200 \mathrm{kPa}$.

Antes da comparação entre ensaios com os dois materiais, é importante mencionar a principal diferença entre eles: o PEAD é aproximadamente quatro vezes mais volumoso que o PEBD.

Através das envoltórias de resistência para diferentes percentuais de PEAD e PEBD para deslocamentos horizontal de 4,5, 9, 14 e 18\%
(Figura 4 a 7), constata-se que, excluindo os ensaios de areia com $1 \%$ de plástico, as amostras de PEAD apresentam coesão e ângulo de atrito maior que as de PEBD. Pode-se observar também através das Tabelas 2 e 3.

Ao excluir as amostras de areia com 1\% de PEAD e PEBD, tem-se que o ângulo de atrito aumenta e depois tende a estabilizar próximo a $14 \%$ de deslocamento, onde seu valor é em torno de $40^{\circ}$ e $34^{\circ}$, respectivamente. Já em relação à coesão, exceto as amostras de areia com $1 \%$ de PEAD e PEBD, os ensaios de areia com PEAD apresentaram valores crescentes até 9 a 14\% de deslocamento e redução em seguida, enquanto que os resultados obtidos nos ensaios de areia com PEBD não apresentaram uma tendência comum, apenas valores superiores ao do ensaio de cisalhamento com $100 \%$ de areia na amostra.

Os valores do ângulo de atrito tiveram uma mobilização de aproximadamente $16^{\circ}$ nas amostras preparadas com $\mathrm{PEAD}$ e $10^{\circ}$ nas amostras
A

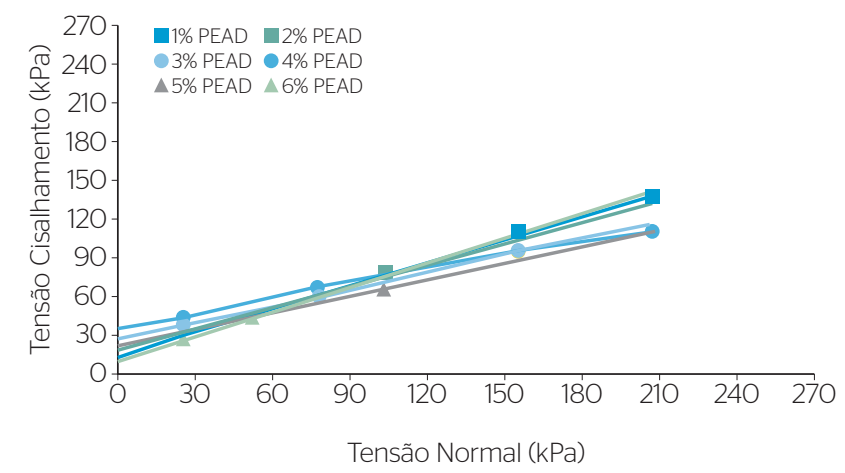

B

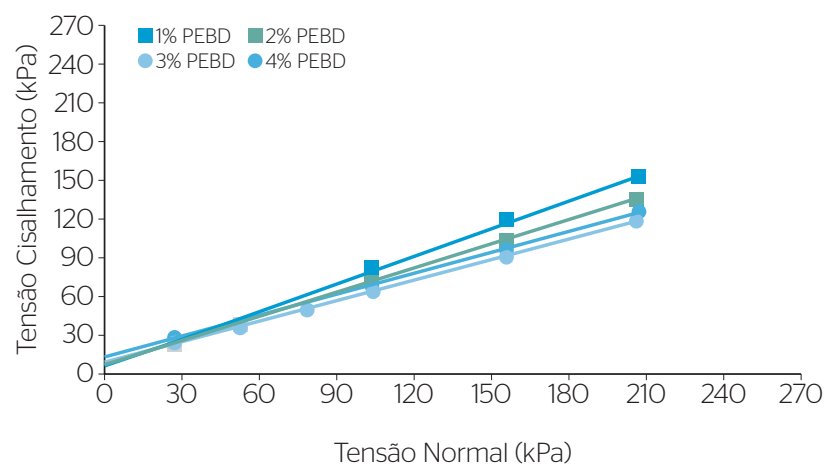

PEAD: polietileno de alta densidade; PEBD: polietileno de baixa densidade.

Figura 4 - Envoltórias de resistência para diferentes percentuais de polietileno - 4,5\% de deslocamento relativo horizontal

A

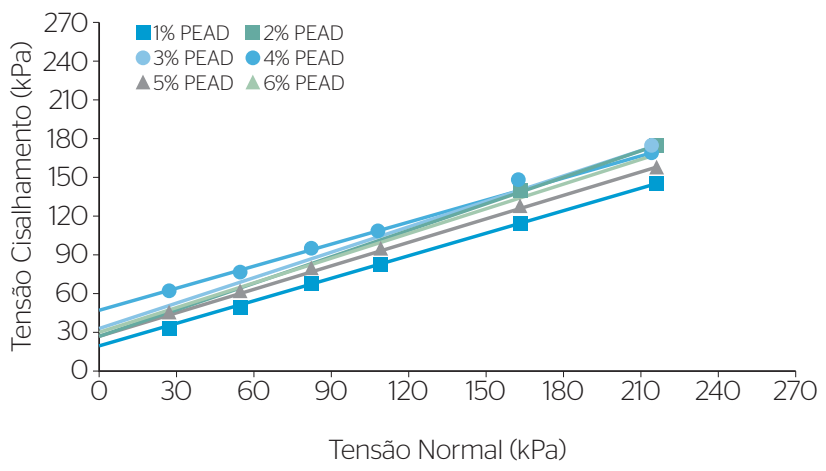

B

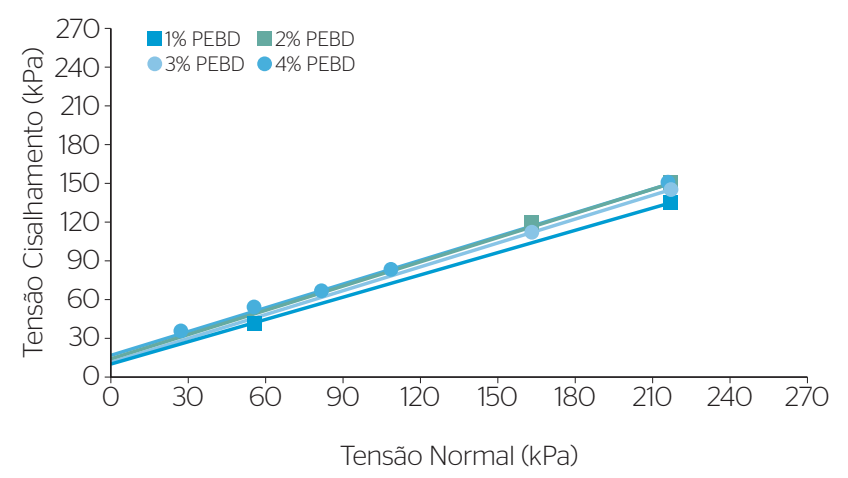

PEAD: polietileno de alta densidade; PEBD: polietileno de baixa densidade.

Figura 5 - Envoltórias de resistência para diferentes percentuais de polietileno - 9\% de deslocamento relativo horizontal. 
A

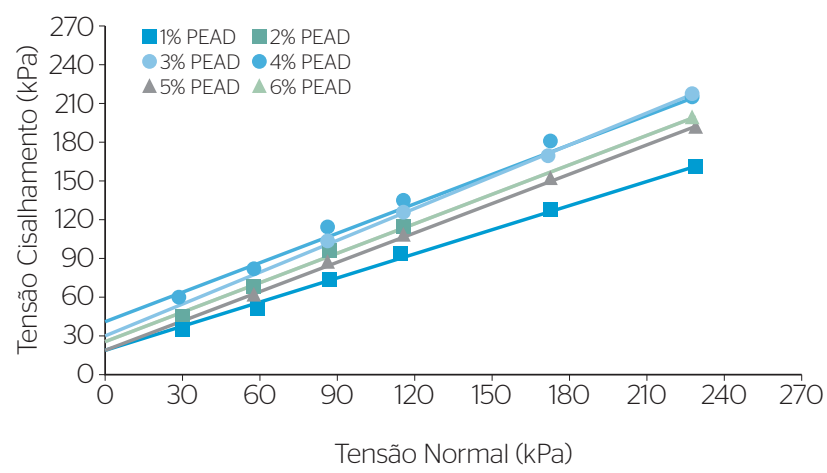

B

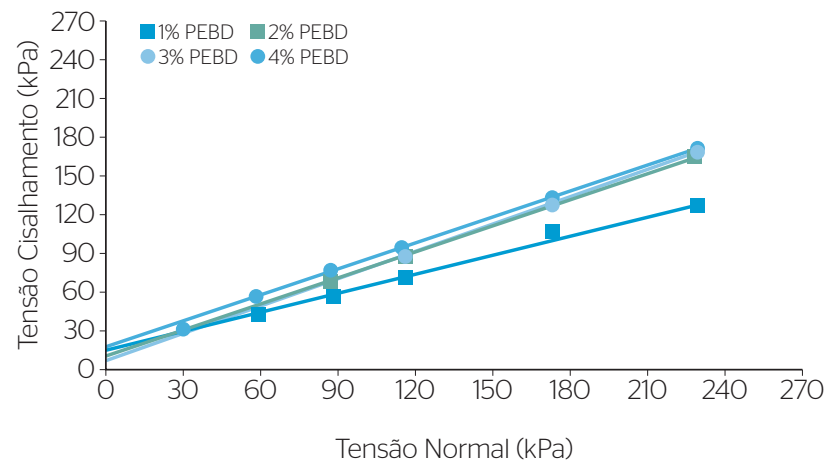

PEAD: polietileno de alta densidade; PEBD: polietileno de baixa densidade.

Figura 6 - Envoltórias de resistência para diferentes percentuais de polietileno - 14\% de deslocamento relativo horizontal.

A

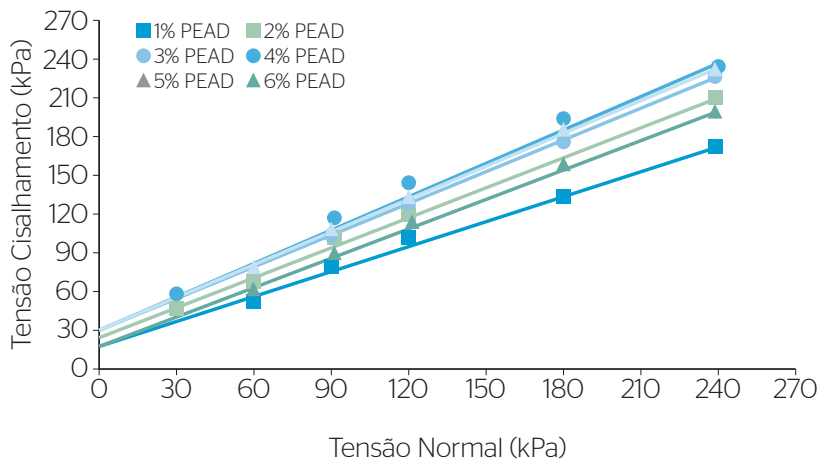

B

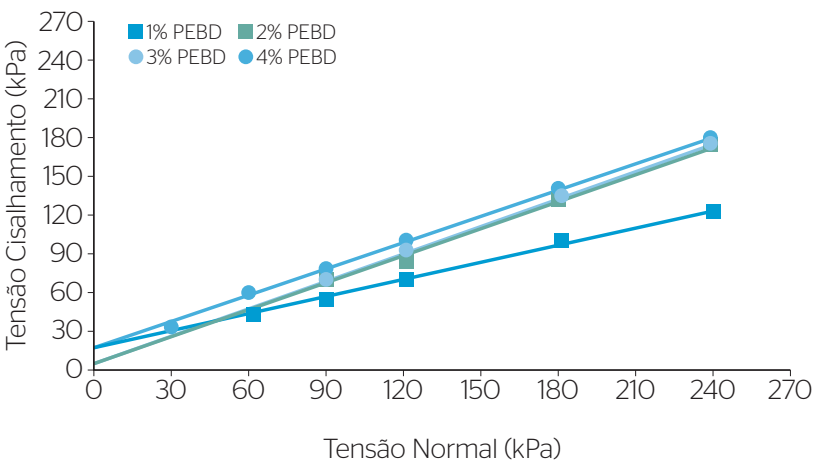

PEAD: polietileno de alta densidade; PEBD: polietileno de baixa densidade.

Figura 7 - Envoltórias de resistência para diferentes percentuais de polietileno - 18\% de deslocamento relativo horizontal.

Tabela 2 - Parâmetros de resistência: coesão e ângulo de atrito para diferentes percentuais de polietileno de alta densidade - a 4,5; 9; 14 e 18\% de deslocamento relativo horizontal.

\begin{tabular}{|c|c|c|c|c|c|c|c|}
\hline \multirow{2}{*}{ Parâmetros } & \multirow{2}{*}{ Deslocamento Relativo Horizontal } & \multicolumn{6}{|c|}{ Percentuais de PEAD } \\
\hline & & $1,0 \%$ & $2,0 \%$ & $3,0 \%$ & $4,0 \%$ & $5,0 \%$ & $6,0 \%$ \\
\hline \multirow{4}{*}{$\mathrm{c}^{\prime}(\mathrm{kPa})$} & $4,5 \%$ & 15,3 & 20,0 & 29,0 & 35,9 & 23,4 & 18,3 \\
\hline & $9 \%$ & 17,6 & 25,6 & 31,1 & 46,0 & 23,5 & 25,5 \\
\hline & $14 \%$ & 18,8 & 26,7 & 28,5 & 42,2 & 19,3 & 29,4 \\
\hline & $18 \%$ & 18,9 & 24,0 & 28,2 & 29,1 & 17,2 & 27,7 \\
\hline \multirow{4}{*}{$f^{\prime}(0)$} & $4,5 \%$ & 31,0 & 28,6 & 22,5 & 19,8 & 23,0 & 24,2 \\
\hline & $9 \%$ & 30,0 & 34,8 & 33,8 & 30,4 & 32,4 & 34,5 \\
\hline & $14 \%$ & 32,0 & 37,1 & 39,7 & 37,5 & 37,1 & 39,5 \\
\hline & $18 \%$ & 32,0 & 37,8 & 39,7 & 40,6 & 37,5 & 41,0 \\
\hline
\end{tabular}

PEAD: polietileno de alta densidade. 
preparadas com PEBD, que representam 67 e $42 \%$ de incremento, respectivamente. A coesão apresentou uma mobilização de até $43 \mathrm{kPa}$ nas amostras preparadas com PEAD e $15 \mathrm{kPa}$ nas amostras preparadas com PEBD, em torno de 1.229 e $429 \%$ de incremento, respectivamente.

Os ensaios de areia com inclusão de PEAD, com exceção de 1\%, apresentam a bilinearidade, conforme resistência proposta por Kölsch $(1993 ; 1995 ; 1996)$ onde as rupturas das fibras são vistas como pontos de descontinuidade, ponto de tensão de tração máxima. Este comportamento se assemelha à trajetória de tensão dos solos reforçados, que apresenta uma coesão fictícia (Figura 8). O mesmo não pode ser visto para os ensaios de areia com PEBD, devido à pouca mobilização das fibras, ocasionada pelo baixo volume de plástico na amostra.
Ao analisar os gráficos de tensão cisalhante versus deslocamento relativo horizontal para tensões normais de 25 e $200 \mathrm{kPa}$ de todos os ensaios de cisalhamento direto realizados (Figura 9 e 10), pode-se observar que em todas as situações as tensões cisalhantes crescem com o aumento da tensão normal aplicada, sendo um aumento maior para os ensaios de amostras de areia com PEAD. Nota-se ainda que, para uma tensão normal de $25 \mathrm{kPa}$, os ensaios com PEBD tiveram um acréscimo na tensão cisalhante muito pequena em relação a amostra com $100 \%$ de areia. As curvas encontram-se praticamente sobrepostas. Já os ensaios com PEAD, apesar do acréscimo também não ter sido grande, ao comparar com os de PEBD, foram quase o dobro para a amostra de areia com $4 \%$ de polímero, por exemplo.

Tabela 3 - Parâmetros de resistência: coesão e ângulo de atrito para diferentes percentuais de polietileno de baixa densidade - a 4,5; 9; 14 e 18\% de deslocamento relativo horizontal.

\begin{tabular}{|c|c|c|c|c|c|}
\hline \multirow{2}{*}{ Parâmetros } & \multirow{2}{*}{ Deslocamento Relativo Horizontal } & \multicolumn{4}{|c|}{ Percentuais de PEBD } \\
\hline & & $1,0 \%$ & $2,0 \%$ & $3,0 \%$ & $4,0 \%$ \\
\hline \multirow{3}{*}{$c^{\prime}(\mathrm{kPa})$} & $4,5 \%$ & 5,8 & 4,7 & 18,8 & 13,5 \\
\hline & $14 \%$ & 16,6 & 10,0 & 8,8 & 17,3 \\
\hline & $18 \%$ & 18,8 & 6,8 & 7,5 & 17,2 \\
\hline \multirow{3}{*}{$f^{\prime}(0)$} & $9 \%$ & 28,8 & 33,1 & 31,7 & 31,8 \\
\hline & $14 \%$ & 25,7 & 34,0 & 34,7 & 33,8 \\
\hline & $18 \%$ & 23,4 & 34,8 & 34,8 & 34,1 \\
\hline
\end{tabular}

PEBD: polietileno de baixa densidade.

Fonte: Salas, 1984.

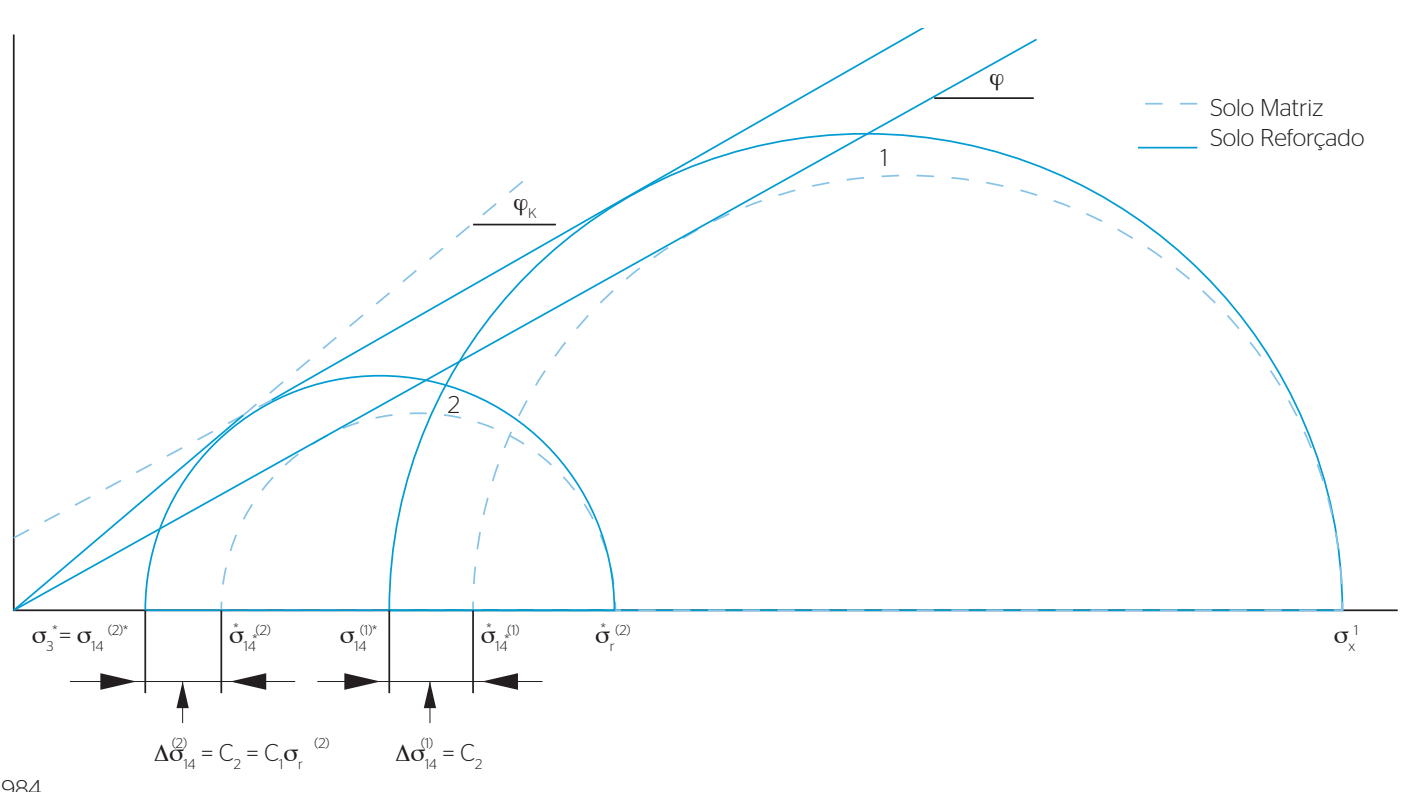

Figura 8 - Coesão fictícia de um solo reforçado. 
A

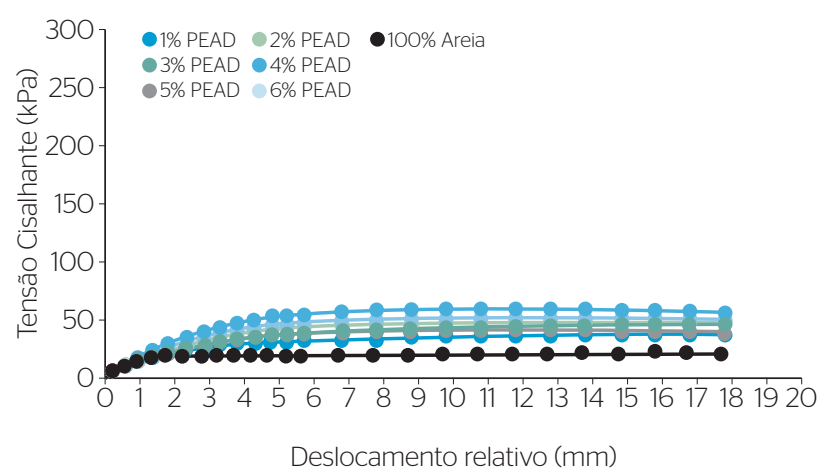

B

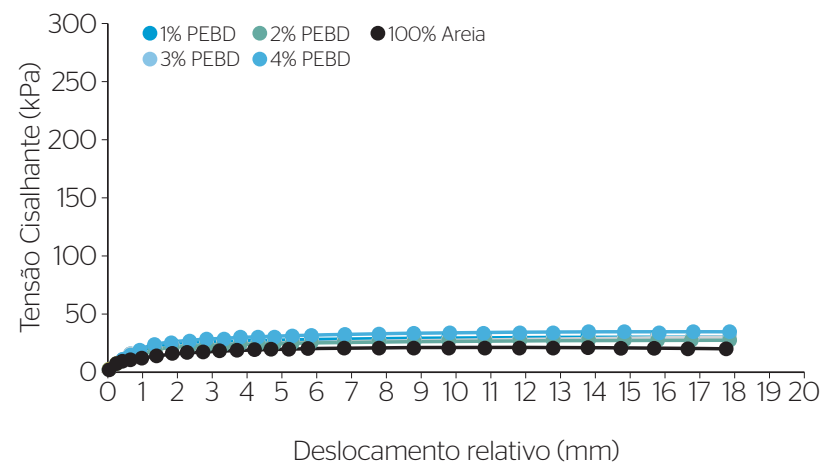

PEAD: polietileno de alta densidade; PEBD: polietileno de baixa densidade.

Figura 9 - Tensão cisalhante x Deslocamento relativo horizontal (A) 100\% Areia e polietileno de alta densidade (B) $100 \%$ e polietileno de baixa densidade - Para Tensão Normal de $25 \mathrm{kPa}$.

A

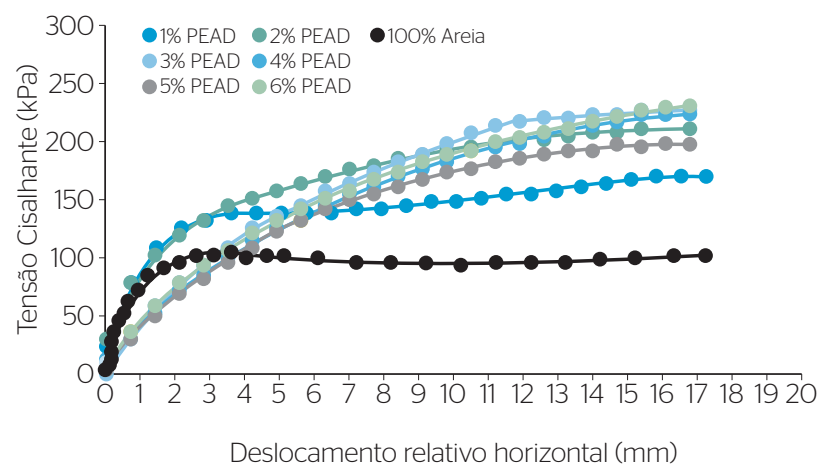

B

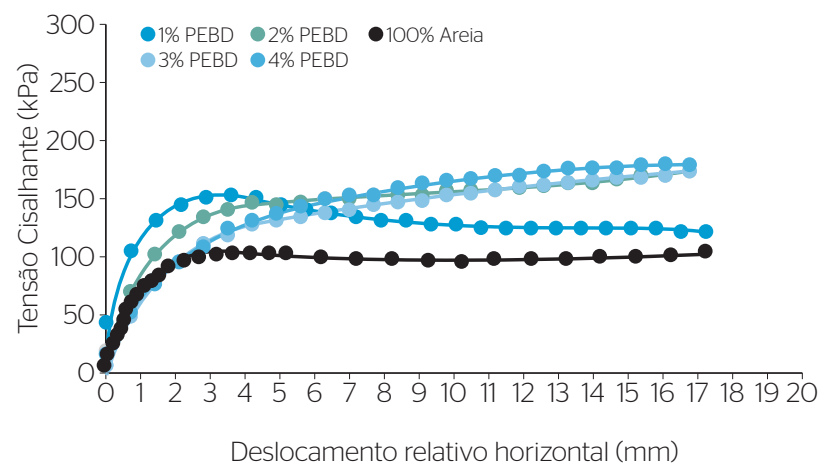

PEAD: polietileno de alta densidade; PEBD: polietileno de baixa densidade.

Figura 10 - Tensão cisalhante versus Deslocamento relativo horizontal (A) 100\% Areia e polietileno de alta densidade (B) $100 \%$ e polietileno de baixa densidade - Para Tensão Normal de $200 \mathrm{kPa}$.

\section{CONCLUSÕES}

A investigação laboratorial dos polietilenos de alta e baixa densidade na mistura com areia, simulando a massa de resíduos sólidos urbanos antiga de uma aterro sanitário, permitiu obter as seguintes conclusões:

- Através do ensaio de tração, verificou-se que o polímero com baixa densidade (PEBD) apresenta o dobro da resistência à tração do polímero de alta densidade (PEAD), devido à sua capacidade de se alongar. Este pode ser um indício do comportamento das amostras pós ensaio. Foi observado que os pedaços de plástico das amostras com PEBD apresentaram-se praticamente intactos, enquanto que, para as amostras de $\mathrm{PEAD}$, os pedaços de plástico apresentaram-se bastante desgastados, rompidos.
- Para cada percentual de PEAD foi observado que a coesão crescia até 9 a $14 \%$ de deslocamento relativo horizontal e depois decaia, enquanto o ângulo de atrito tendia a crescer com o aumento do deslocamento horizontal, comprovando que o material simulava de fato lixo antigo.

- Ao excluir a amostra preparada com 1\% de PEBD, tem-se que o ângulo de atrito aumenta e depois tende a estabilizar em torno de $34^{\circ}$ próximo a $14 \%$ de deslocamento. Quanto à coesão, os resultados obtidos nos ensaios com PEBD não apresentaram uma tendência comum, apenas que apresentam valores superiores ao do ensaio de cisalhamento sem adição de plásticos na amostra.

- Comparando os ensaios de cisalhamento direto, pode-se observar que só a partir da inclusão de 3\% de PEBD é que as amostras 
começam a ter um comportamento semelhante aos ensaios de $\mathrm{PEAD}$, devido à diferença volumétrica entre eles. Os corpos de prova com PEAD apresentam cerca de quatro vezes o volume de plástico dos com PEBD. Isso pode ser uma justificativa para o comportamento dos ensaios com PEBD terem se apresentado diferentes dos ensaios com PEAD.

- Tomando por base a amostra sem polímeros, os valores do ângulo de atrito tiveram um incremento de aproximadamente $16^{\circ}$ nas amostras preparadas com PEAD e $10^{\circ}$ nas amostras preparadas com PEBD, que representam 67 e 42\%, respectivamente. A coesão apresentou um incremento de até $43 \mathrm{kPa}$ nas amostras preparadas com PEAD e $15 \mathrm{kPa}$ nas amostras preparadas com PEBD, em torno de 1.229 e $429 \%$, respectivamente.

É importante lembrar que, neste trabalho, foram utilizadas sacolas plásticas de supermercado para representar os polímeros PEAD, porém este material ainda pode ser encontrado em outras embalagens comercializadas no mercado. Desta forma, caso seja validada a retirada destas sacolas de circulação e, consequentemente, dos aterros sanitários brasileiros, ainda existirão PEAD e PEBD, assim como os demais plásticos apresentados na composição dos aterros, que não foram estudados neste trabalho. Portanto, a redução destes plásticos pouco influenciaria nos parâmetros de resistência para efeito de estabilidade de taludes dos aterros.

Com respeito à polêmica do consumo das sacolas plásticas e à possível retirada destas dos aterros de RSU, seria lógico pensar que os parâmetros de resistência de cisalhamento (coesão e ângulo de atrito) poderiam ser reduzidos, podendo causar danos futuros na sua estabilidade. Porém, como o consumo de plástico aumenta com o desenvolvimento econômico da região, o consumo e descarte de embalagens de PEBD tende aumentar, assim como os demais plásticos encontrados no mercado. Desta forma, através dos resultados aqui apresentados, conclui-se que pode ser descartada preocupação por problemas de estabilidade de taludes dos aterros devido à retirada das sacolas de supermercado.

\section{REFERÊNCIAS}

AMERICAN SOCIETY FOR TESTING AND MATERIALS - ASTM. D882 (2012) Standard Test Method for Tensile Properties of Thin Plastic Sheeting. $12 \mathrm{p}$.

ALCÂNTARA, P.B. (2007) Avaliação da Influência da Composição de Resíduos Sólidos Urbanos no Comportamento de Aterros Simulados. Tese (Doutorado em Engenharia Civil) - Universidade Federal de Pernambuco, Recife.

BELO HORIZONTE. Lei Municipal no 9.529/08 (2008) Dispõe sobre a substituição do uso de saco plástico de lixo e de sacola plástica por saco de lixo ecológico e sacola ecológica, e dá outras providências.

CANEVAROLO Jr, S.V. (2007) Técnicas de Caracterização de Polímeros. São Paulo: Artliber.

CINTRA, L. (2011) Entenda a polêmica da proibição das sacolas plásticas. Disponível em: <http://super.abril.com.br/blogs/ ideias-verdes/entenda-a-polemica-da-proibicao-das-sacolasplasticas/>

FARIA, W. (2012) Mercados continuarão substituindo sacolas descartáveis. Disponível em: <http://deolhonailha-vix.blogspot.com.br/ 2012/06/proibicao-de-sacolas-plasticas-nos.html>
JESSBERGER, H.L. SYLLWASSCHY, O.; KOCKEK, R. (1995) Investigation of waste body-behavior and waste structure interaction. In: Proceeding of the 5 Sardinia International Landfill Symposium S. Margherita D Pula, Cagliari, v. II, p. 731-743.

KÖLSCH, F. (1993) The Bearing Behaviour of Domestic Waste and Related Consequences for Stability. In: Proceedings of the 4th International Landfill Symposium, Cagliari (Italy), v. 2, p. 1393-1410.

KÖLSCH, F. (1995) Material Values for Some Mechanical Properties of Domestic Waste. In: Proceedings of the 5th International Landfill Symposium, Cagliari (Italy), v. 2, p. 711-729

KÖLSCH, F. (1996) Der Einfluß der Faserbestandteile auf die Scherfestigkeit von Siedlungsabfall. Mitteilungen des LeichtweißInstitutes für Wasserbau der TU Braunschweig. Leichtweiss-Ins,

SÃO PAULO. Lei Municipal no 15.374 (2011) Dispõe sobre a proibição da distribuição gratuita ou venda de sacolas plásticas a consumidores em todos os estabelecimentos comerciais do Município de São Paulo, e dá outras providências.

SILVA, E.M. (2005) Desenvolvimento de um Equipamento para Ensaios em Embalagens Plásticas Flexíveis. Dissertação (Mestrado em Engenharia Mecânica) - Universidade Federal de Pernambuco, Recife. 